\title{
Role of RsmA in the regulation of swarming motility and virulence factor expression in Proteus mirabilis
}

\author{
Shwu-Jen Liaw, ${ }^{1}$ Hsin-Chih Lai, ${ }^{1}$ Shen-Wu Ho, ${ }^{1}$ Kwen-Tay Luh ${ }^{2}$ and \\ Won-Bo Wang ${ }^{3}$
}

\author{
Correspondence \\ Won-Bo Wang \\ wbwang@ha.mc.ntu.edu.tw
}

Received 11 July 2002

Accepted 12 August 2002

\author{
${ }^{1,3}$ School and Graduate Institute of Medical Technology ${ }^{1}$ and Graduate Institute of Microbiology ${ }^{3}$, \\ College of Medicine, National Taiwan University, 1 Jen Ai Road, 1st Section, Taipei, Taiwan, Republic \\ of China \\ ${ }^{2}$ Department of Laboratory Medicine, National Taiwan University Hospital, Taipei, Taiwan, Republic of \\ China
}

\begin{abstract}
Swarming by Proteus mirabilis involves differentiation of typical short vegetative rods into filamentous hyper-flagellated swarm cells that undergo cycles of rapid and co-ordinated population migration across surfaces and exhibit high levels of virulence gene expression. RsmA (repressor of secondary metabolites) and CsrA, its homologue in Escherichia coli, control many phenotypic traits, such as motility and pathogenesis in Erwinia species, glycogen biosynthesis, cell size and biofilm formation in Escherichia coli and swarming motility in Serratia marcescens. To investigate the role of RsmA in Proteus mirabilis, the rsmA gene from Proteus mirabilis (hereafter referred to as $r s m A_{P m}$ ) was cloned. RsmA $A_{P m}$ showed high sequence similarity to Escherichia coli CsrA and RsmA cloned from Erwinia carotovora subsp. carotovora, Serratia marcescens, Haemophilus influenzae and Bacillus subtilis and could complement an Escherichia coli csrA mutant in glycogen synthesis. A low-copy-number plasmid carrying $r s m A_{P_{m}}$ expressed from its native promoter caused suppression of swarming motility and expression of virulence factors in Proteus mirabilis. mRNA stability assays suggested that RsmA $A_{P m}$ inhibited virulence factor expression through promoting mRNA degradation. RsmA homologues cloned from Serratia marcescens and Erwinia carotovora subsp. carotovora could also inhibit swarming and virulence factor expression in Proteus mirabilis.
\end{abstract}

\section{INTRODUCTION}

Swarming motility is a type of population migration behaviour characteristic of some bacteria on solid media (Eberl et al., 1999; Harshey, 1994; Harshey \& Matsuyama, 1994). It is a cyclic process and is closely correlated with the expression of virulence factors in both Proteus and Serratia (Allison \& Hughes, 1991; Allison et al., 1992; Givskov et al., 1997; Liaw et al., 2000). In these bacteria, swarming migration involves the co-ordinated differentiation of short, motile vegetative cells bearing a few peritrichous flagella into multinucleate, aseptate swarm cells of up to 40 times the vegetative cell length and with a much greater surface density of flagella (Allison et al., 1992; Givskov et al., 1997). Swarming is influenced by multiple environmental signals, such as cell density and the presence of particular amino acids and possibly peptides (Allison et al., 1993; Gaisser \& Hughes, 1997; Rauprich et al.,

The nucleotide and deduced amino acid sequences of Proteus mirabilis rsmA are available as supplementary material in JMM Online (http:// jmm.sgmjournals.org/).

The GenBank/EMBL/DDBJ accession number for the DNA sequence of Proteus mirabilis rsmA reported in this paper is AF403736.
1996). Characterization of swarming-defective Proteus transposon mutants has indicated that many proteins are involved in the regulation of differentiation and subsequent swarming migration (Belas et al., 1991, 1995; Gygi et al., 1995a, b, 1997; Fraser \& Hughes, 1999). These include FlhA, a protein involved in flagellum assembly and swarm-cell differentiation (Gygi et al., 1995a), FlgN, a substrate-specific flagellar chaperone that prevents oligomerization of hook-associated proteins and thus facilitates flagellum assembly (Fraser et al., 1999), FlhD $\mathrm{C}_{2}$ (heterotetramers of FlhD and FlhC), a transcription activator that regulates the expression of the flagellar regulon (Fraser \& Hughes, 1999), Umo proteins that upregulate the flhDC operon during differentiation (Fraser \& Hughes, 1999), Lrp, a global transcriptional regulator that links physiological signals to swarming differentiation (Fraser \& Hughes, 1999), CcmA, a protein that regulates cell shape and thus influences multicellular swarming (Hay et al., 1999), and RsbA, a putative bacterial two-component sensor kinase involved in the regulation of swarming (Liaw et al., 2001). Of these, FlhDC, Lrp and the Umo proteins probably function as part of a broader regulatory network that may include bacterial two-component systems and the chemotaxis phosphorelay (Fraser \& Hughes, 1999). 
RsmA is a homologue of CsrA (for carbon storage regulator) (Romeo et al., 1993; Cui et al., 1995), a critical component of the Escherichia coli Csr system, a global regulatory system that represses a variety of stationary-phase genes (Romeo et al., 1993). CsrA inhibits glycogen biosynthesis and catabolism, gluconeogenesis and biofilm formation in Escherichia coli (Romeo et al., 1993; Romeo, 1998). CsrA represses glycogen synthesis by causing rapid mRNA decay (Liu et al., 1995). This leads to a decrease in intracellular levels of glycogen biosynthesis enzymes, which, in turn, decreases the rate of glycogen biosynthesis. A second component of the Csr regulatory system, CsrB, a non-coding RNA molecule, acts as an antagonist of CsrA, presumably by sequestering it (Liu et al., 1997; Liu \& Romeo, 1997). Searches in the GenBank databases have shown that homologues of $c s r A$ can be found in many Gram-negative bacteria and some Gram-positive bacteria (White et al., 1996). RsmA, a homologue of CsrA, represses stationary-phase genes in Pseudomonas fluorescens (Blumer et al., 1999) and negatively controls several genes involved in motility, secondary metabolism, pathogenesis and quorum-sensing in Erwinia carotovora subsp. carotovora (Cui et al., 1995; Liu et al., 1998; Mukherjee et al., 1996).

Proteus mirabilis is an important pathogen of the urinary tract, especially in patients with indwelling urinary catheters (Warren et al., 1982). It is believed that the ability of Proteus mirabilis to colonize the urinary tract is associated with its swarming motility. Moreover, the ability of Proteus mirabilis to express virulence factors, including urease, protease, haemolysin and flagellin, and to invade human uroepithelial cells is coupled to swarming differentiation (Allison \& Hughes, 1991; Allison et al., 1992; Liaw et al., 2000). RsmA has been shown to repress swarming motility and the expression of virulence factors in many Erwinia species (Cui et al., 1995; Liu et al., 1998; Mukherjee et al., 1996). However, in Escherichia coli, CsrA, a homologue of RsmA, positively regulates swarming motility and flhDC expression (Wei et al., 2001). In this study, the rsmA allele of Proteus mirabilis has been identified and cloned and the effect of $\mathrm{RsmA}_{\mathrm{Pm}}$ (RsmA encoded by Proteus mirabilis) on the swarming behaviour and the expression of virulence factors, including haemolysin, protease, urease and flagellin, in Proteus mirabilis has been investigated. The trans-acting

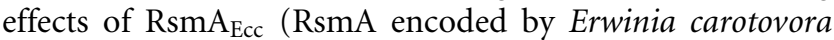
subsp. carotovora) and RsmA $\mathrm{Sm}_{\mathrm{Sm}}$ (RsmA encoded by Serratia marcescens) (Ang et al., 2001) on swarming-related traits of Proteus mirabilis were also examined.

\section{METHODS}

Enzymes and chemicals. DNA restriction and modification enzymes were purchased from Boehringer. Taq polymerase and PCR-related products were from Perkin Elmer or Takara Biomedicals. Other chemicals were purchased from Sigma.

Bacterial strains, plasmids and culture conditions. The bacterial strains and plasmids used are described in Table 1. Bacteria were cultured at $37^{\circ} \mathrm{C}$ in Luria-Bertani (LB) medium. Swarming motility was examined on swarming-agar plates (LB solidified with $1.5 \%$ agar) by inoculating $5 \mu \mathrm{l}$ of an overnight broth culture on to the centre of the agar plate. The plates were dried before inoculation and incubated at $37^{\circ} \mathrm{C}$. Hourly increases in the optical density of broth cultures at $600 \mathrm{~nm}$ were taken as a measurement of the growth rate.

Recombinant DNA techniques. Standard protocols were used for Southern hybridization, isolation of plasmid and chromosomal DNA, transformation, electroporation, PCR, restriction endonuclease digestion, agarose gel electrophoresis, recovery of DNA from agarose gels and the ligation of DNA fragments. DNA sequencing and analysis were performed using a Perkin-Elmer Autosequencer model 373A with a Taq DyeDeoxy terminator cycle sequencing kit (Applied Biosystems). The DNA sequence of PCR products was confirmed by sequencing both strands. DNA sequence similarity searches of GenBank were performed using programs of the University of Wisconsin Genetics Computer Group (Devereux et al., 1984). Protein primary sequence comparisons were performed using BLASTP via the NCBI internet homepage (http:// www.ncbi.nlm.nih.gov/). Promoter prediction was made through the Berkeley Drosophila Genome Project (http://www.fruitfly.org/). The oligonucleotide primers used in PCR and sequencing are summarized in Table 2.

Cloning of Proteus mirabilis P19 rsmA. The PCR primers csrAR and csrAF (Table 2), designed according to conserved regions in Escherichia coli csrA and Erwinia carotovora subsp. carotovora rsmA, were used to amplify a conserved DNA fragment from Proteus mirabilis P19 chromosomal DNA. A single DNA band with the expected size of $156 \mathrm{bp}$ was detected. This 156-bp DNA fragment, which showed high sequence identity to Escherichia coli csrA and Erwinia carotovora subsp. carotovora $\operatorname{rsm} A$, was used as a hybridization probe in the following cloning protocol (Fig. 1). Chromosomal DNA prepared from Proteus mirabilis P19 was first digested with EcoRV, followed by ligation to EcoRV-digested pZErO2.1 (Table 1). The $5^{\prime}$ half and upstream region of $r s m A_{\mathrm{Pm}}(2600 \mathrm{bp})$ was amplified by PCR using the primers M13R and csrAR (Table 2) and the $3^{\prime}$ half and downstream region (500 bp) was amplified using the primers csrAF and M13F (Table 2). Southern hybridization using the labelled 156-bp DNA fragment as a probe and DNA sequencing confirmed that the amplified DNA fragments contained the $r s m A$-like sequence. The full-length $r s m A_{\mathrm{Pm}}$ was subsequently amplified using the primers rsmAF and rsmAR (Table 2), designed from the $5^{\prime}$ and $3^{\prime}$ flanking regions of $r s m A_{\mathrm{Pm}}$. The amplified $r s m A_{\mathrm{Pm}}$ and its flanking sequences were then cloned into pCR2.1 to generate $\mathrm{pSJ}$.

Complementation of an Escherichia coli csrA mutant with rsmA $_{\mathbf{P m}}$. The csrA-defective Escherichia coli mutant TR1-5BW3414 (Romeo et al., 1993) was transformed with pACYC184, pRsmA (pACYC184 containing $r s m A_{\mathrm{Pm}}$ ), pSJ (pCR2.1 containing $r s m A_{\mathrm{Pm}}$ ) or pCSR10 (pUC19 containing csrA). Chloramphenicol- or ampicillinresistant clones were selected and subjected to plasmid preparation to confirm the presence of the appropriate plasmid. These transformed strains together with the wild-type Escherichia coli strain, BW3414 $\left(c s r A^{+}\right)$, and the TR1-5BW3414 mutant were inoculated on to plates containing Kornberg medium ( $1 \%$ glucose, $0 \cdot 85 \% \mathrm{KH}_{2} \mathrm{PO}_{4}, 1 \cdot 1 \%$ $\mathrm{K}_{2} \mathrm{HPO}_{4}, 0 \cdot 6 \%$ yeast extract, $1 \cdot 5 \%$ agar). After incubation overnight at $37^{\circ} \mathrm{C}$, the plates were treated with iodine solution $\left(0 \cdot 01 \mathrm{M} \mathrm{I}_{2}, 0.03 \mathrm{M}\right.$ $\mathrm{KI})$ to detect the accumulation of glycogen produced by these strains.

Measurement of cell length, flagellin level and haemolysin, urease and protease activities. Measurements of cell length, flagellin level and haemolysin, urease and protease activities were performed as described previously (Liaw et al., 2001). Briefly, $150 \mu$ l aliquots of stationary-phase LB cultures from pRsmA-containing and pACYC184containing Proteus mirabilis were spread on to LB agar plates and incubated at $37^{\circ} \mathrm{C}$ for various lengths of time. After incubation, cells from the entire surface were harvested by washing with $5 \mathrm{ml} \mathrm{LB}$. These 
Table 1. Bacterial strains and plasmids

$\mathrm{Ap}^{\mathrm{r}}$, Ampicillin resistance; $\mathrm{Cm}^{\mathrm{r}}$, chloramphenicol resistance; $\mathrm{Km}^{\mathrm{r}}$, kanamycin resistance; $\mathrm{Tc}^{\mathrm{r}}$, tetracycline resistance.

\begin{tabular}{|c|c|c|}
\hline Bacterial strain or plasmid & Relevant characteristics & Source or reference \\
\hline \multicolumn{3}{|l|}{ Strains } \\
\hline Proteus mirabilis P19 & Clinical isolate & Liaw et al. (2001) \\
\hline Escherichia coli Top 10 & For TA cloning & Invitrogen \\
\hline Escherichia coli BW3414 & Parental strain of TR1-5BW3414 & Romeo et al. (1993) \\
\hline Escherichia coli TR1-5BW3414 & $\operatorname{csr} A:: k a n R$ & Romeo et al. (1993) \\
\hline \multicolumn{3}{|l|}{ Plasmids } \\
\hline pZErO2.1 & Cloning vector, $\mathrm{Km}^{\mathrm{r}}$ & Invitrogen \\
\hline pCR2.1 & TA cloning vector, $\mathrm{Ap}^{\mathrm{r}} \mathrm{Km}^{\mathrm{r}}$ & Invitrogen \\
\hline pACYC184 & $\mathrm{Tc}^{\mathrm{r}} \mathrm{Cm}^{\mathrm{r}}$, replicon $\mathrm{P} 15 \mathrm{~A}$ & Biolabs \\
\hline pSJ & Full-length $r s m A_{\mathrm{Pm}}$ in pCR2.1 & This study \\
\hline pRsmA & Full-length $r s m A_{\mathrm{Pm}}$ in pACYC184 & This study \\
\hline pSA1 & Full-length $r s m A_{\mathrm{Ecc}}$ in pACYC184 & Ang et al. (2001) \\
\hline pSA4 & Full-length $r s m A_{\mathrm{Sm}}$ in pACYC184 & Ang et al. (2001) \\
\hline pCSR10 & Full-length $c s r A$ in pUC19 & Romeo et al. (1993) \\
\hline
\end{tabular}

Table 2. Nucleotide sequences of primers used in PCR and sequencing

\begin{tabular}{|c|c|}
\hline Primer & Sequence $\left(5^{\prime} \rightarrow 3^{\prime}\right)$ \\
\hline \multicolumn{2}{|c|}{ Cloning Proteus mirabilis rsmA homologue } \\
\hline $\operatorname{csrAF}$ & ATGCTGATTCTGACTCGTCGA \\
\hline csrAR & GGATACGCTGGTAGATCTCTTCACGGT \\
\hline \multicolumn{2}{|c|}{ Amplification of full-length Proteus mirabilis rsmA } \\
\hline rsmAF & GCTAAGAATGTGAAAGGTAT \\
\hline rsmAR & TCATTCAAGCATTTTATTTC \\
\hline \multicolumn{2}{|c|}{ Haemolysin gene mRNA-stability assay } \\
\hline $\mathrm{HpmF}$ & TAAAATCGATGAACGCACAG \\
\hline HpmR & GATTTTTCCTGCATTGATAG \\
\hline \multicolumn{2}{|c|}{ Proteus mirabilis rsmA homologue upstream sequencing } \\
\hline rsmR & АTTTACGCCAATACGTACCT \\
\hline fala & GGATAACGCTTTTTCAGGTA \\
\hline \multicolumn{2}{|c|}{ Proteus mirabilis rsmA homologue cloning by reverse PCR } \\
\hline $\operatorname{M13F}(-20)^{*}$ & GTAAAACGACGGCCAG \\
\hline M13R & CAGGAAACAGCTATGAC \\
\hline
\end{tabular}

*Also used for $r s m A$ downstream sequencing.

cells were then subjected to several assays. For cell-elongation measurements, bacteria were fixed in $4 \%$ paraformaldehyde and examined by light microscopy at a magnification of $1000 \times$ under oil-immersion using an Olympus $\mathrm{BH} 2$ microscope equipped with a graticule. The lengths of 100 cells in each sample were determined and the mean calculated. Cell membrane-associated haemolysin activity was assayed as described previously (Koronakis et al., 1987). Protease activity was determined by the method of Gibson \& Macfarlane (1988). The urease activity of whole-cell suspensions was determined by the phenol red colorimetric assay (Jones \& Mobley, 1988). Flagellin determination was performed as described previously (Gygi et al., 1995a).
mRNA stability assay. Proteus mirabilis $\mathrm{P} 19$ cells transformed with the pACYC184 vector or pRsmA were grown at $37^{\circ} \mathrm{C}$ in $\mathrm{LB}$ to an $\mathrm{OD}_{600}$ of $0 \cdot 5$. At $0,2,4,6$ and $8 \mathrm{~min}$ after addition of rifampicin to a final concentration of $400 \mu \mathrm{g} \mathrm{ml}^{-1}$ to block further transcription, aliquots $(10 \mathrm{ml})$ were collected in tubes containing $1 \mathrm{ml}$ freshly prepared stop solution ( $5 \%$ phenol in ethanol). Total RNA was extracted by the hotphenol method (Magni et al., 1995) and Northern blot analysis was performed to detect the haemolysin mRNA as described previously (Liu et al., 1998). RNA samples were loaded on formaldehyde (6\%)/agarose $(1.2 \%)$ gels and electrophoresed in MOPS buffer $(0.02 \mathrm{M}$ MOPS, $0 \cdot 005 \mathrm{M}$ sodium acetate, $0 \cdot 001 \mathrm{M}$ EDTA). After transfer to a nitrocellulose membrane which was washed in $2 \times \operatorname{SSC}(0 \cdot 3 \mathrm{M} \mathrm{NaCl}, 0.03 \mathrm{M}$ trisodium citrate), the RNAs were cross-linked to the membrane by UV irradiation. The haemolysin gene $(h p m A)$ probe $(1 \mathrm{~kb})$ was amplified from genomic DNA with a PCR DIG Probe Synthesis kit (Boehringer Mannheim) using primers HpmF and HpmR (Table 2), designed from the $h p m A$ sequence (Uphoff \& Welch, 1990). Pre-hybridization ( $4 \mathrm{~h}$ at $58{ }^{\circ} \mathrm{C}$ ) and hybridization $\left(18 \mathrm{~h}\right.$ at $58^{\circ} \mathrm{C}$ ) were performed in DIG Easy $\mathrm{Hyb}^{*}$ buffer (Boehringer Mannheim). After hybridization, membranes were washed twice for $5 \mathrm{~min}$ at $50{ }^{\circ} \mathrm{C}$ in $2 \times$ SSC, $0 \cdot 1 \%$ SDS, then twice for $15 \mathrm{~min}$ at $50{ }^{\circ} \mathrm{C}$ in $0 \cdot 1 \times \mathrm{SSC}, 0 \cdot 1 \% \mathrm{SDS}$, and examined by using the DIG DNA Luminescence Detection kit (Boehringer Mannheim). A $0 \cdot 24-9 \cdot 5 \mathrm{~kb}$ RNA ladder (Gibco-BRL) was used as a size marker.

\section{RESULTS}

\section{Cloning of the rsmA gene from Proteus mirabilis}

In order to know whether rsmA exists in Proteus mirabilis and might play a role in the regulation of Proteus mirabilis swarming and virulence factor expression, $r s m A_{\mathrm{Pm}}$ was first cloned. The PCR primers csrAR and csrAF (Table 2), designed according to conserved regions in Escherichia coli $c s r A$ and Erwinia carotovora subsp. carotovora $r s m A$, amplified a conserved DNA fragment of Proteus mirabilis P19 chromosomal DNA to give a single DNA band with the expected size of $156 \mathrm{bp}$. This had high DNA sequence 


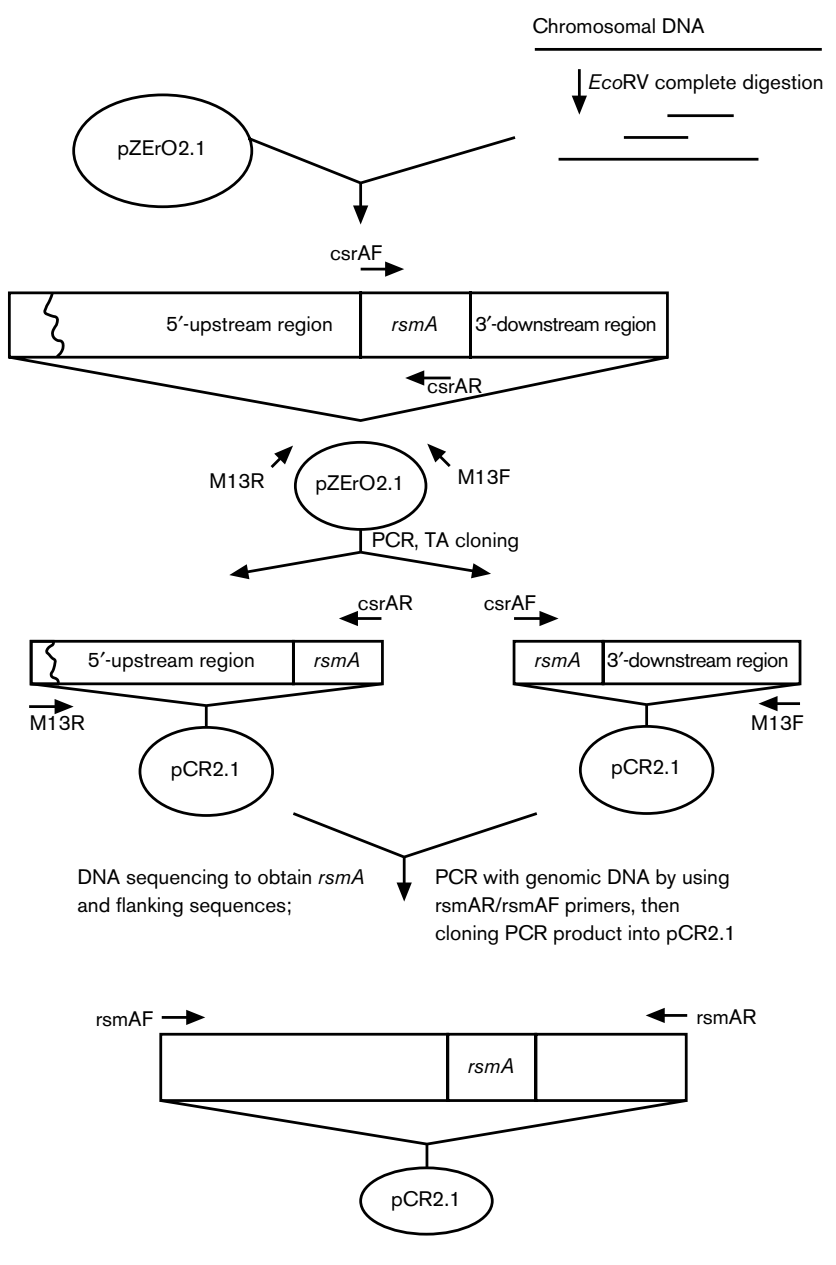

Fig. 1. Scheme for cloning of Proteus mirabilis rsmA. For details, refer to Methods.

identity to sequences of Escherichia coli csrA and Erwinia carotovora subsp. carotovora rsmA (unpublished observations). Despite repeated attempts, it was not possible to clone the complete $r s m A_{\mathrm{Pm}}$ gene via a colony hybridization protocol (a genomic library had been constructed in the high-copy-number plasmid pZErO2.1 and it is possible that overexpression of $r s m A_{\mathrm{Pm}}$ was lethal). Therefore, PCR was used to clone the complete $r s m A_{\mathrm{Pm}}$ gene as described. The nucleotide sequence and the deduced amino acid sequence of the open reading frame $(\mathrm{ORF})$ of the $r s m A_{\mathrm{Pm}}$ gene-containing fragment are available as supplementary material in JMM Online (http://jmm.sgmjournals.org/). The fragment contains $1021 \mathrm{bp}$ in total and an ORF (nt 555-743) that could encode a $6 \cdot 8-\mathrm{kDa}$ polypeptide of 62 amino acid residues. A putative Shine-Dalgarno sequence $\left(5^{\prime}\right.$-AGGAG- $\left.3^{\prime}\right)$ is located 6 bp upstream of the ATG start codon. Putative -10 and -35 regions are also shown. Fig. 2 shows the alignment of deduced amino acid sequences among Escherichia coli CsrA, Proteus mirabilis $\mathrm{RsmA}_{\mathrm{Pm}}$, Erwinia carotovora subsp.

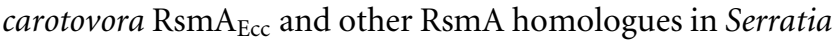
marcescens, Haemophilus influenzae and Bacillus subtilis.

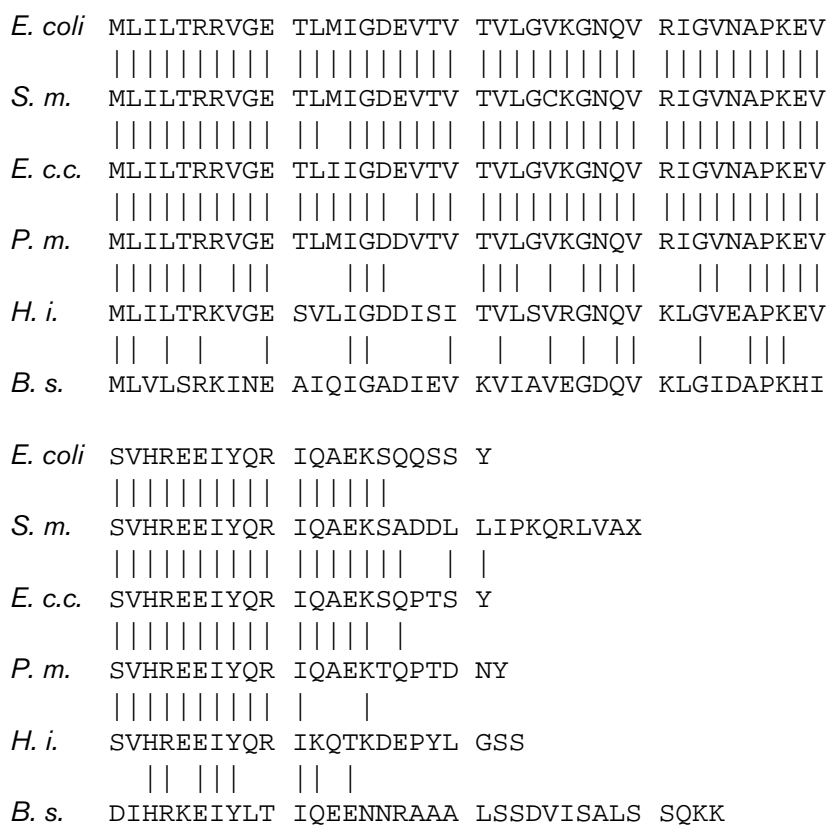

Fig. 2. Alignment of the deduced amino acid sequences of RsmA homologues in Escherichia coli K-12 (E. coli; Romeo et al., 1993), Serratia marcescens (S. m.; Ang et al., 2001), Erwinia carotovora subsp carotovora (E. c. c.; Cui et al., 1995), Proteus mirabilis (P. m.), Haemophilus influenzae (H. i.; Fleischmann et al., 1995) and Bacillus subtilis (B. s.; Mirel \& Chamberlin, 1989). Vertical lines indicate residues identical to those in Escherichia coli K-12.

Amino acid sequence comparison revealed that $\mathrm{RsmA}_{\mathrm{Pm}}$ showed $96 \%$ identity to Escherichia coli CsrA and RsmA $A_{S m}$, $94 \%$ identity to $\mathrm{RsmA}_{\mathrm{Ecc}}$ and respectively 70 and $45 \%$ identity to RsmA from $H$. influenzae and B. subtilis. As with Escherichia coli CsrA (Romeo, 1998), the predicted product of $r s m A_{\mathrm{Pm}}$ also contains a putative RNA-binding domain (see supplementary material) that is similar to the $\mathrm{KH}$ (K protein homology) motif found only in proteins associated with RNA (Siomi et al., 1994).

\section{Complementation of an Escherichia coli csrA mutant with rsmA $_{\mathrm{Pm}}$}

To investigate whether $\mathrm{RsmA}_{\mathrm{Pm}}$ had similar functions to Escherichia coli CsrA, an Escherichia coli csrA-defective mutant, TR1-5BW3414 (Romeo et al., 1993), was transformed respectively with the vectors pACYC184, pRsmA $\left(r s m A_{\mathrm{Pm}}\right.$ in low-copy-number vector pACYC184), pSJ $\left(r s m A_{\mathrm{Pm}}\right.$ in high-copy-number vector pCR2.1) or pCSR10 ( $c s r A$ in high-copy-number vector pUC19). The ability of $\mathrm{RsmA}_{\mathrm{Pm}}$ and CsrA to suppress the glycogen-overproducing activity of the TR1-5BW3414 mutant was tested. As shown in Fig. 3, the TR1-5BW3414 mutant and its pACYC184 transformant stained dark-brown due to excess glycogen accumulation. The TR1-5BW3414 mutant transformed with pRsmA stained yellowish brown, similar to the staining 


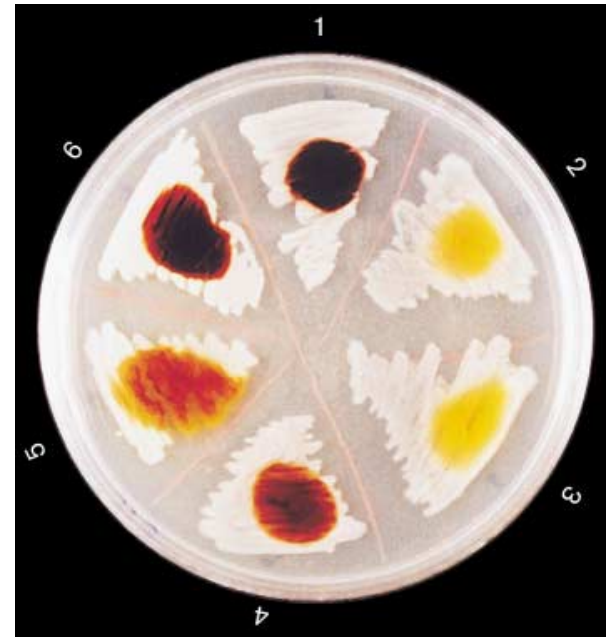

Fig. 3. Complementation of an Escherichia coli csrA mutant with $r_{s m} A_{P m}$ detected by iodine staining. Cultures were streaked on to Kornberg medium and incubated overnight at $37^{\circ} \mathrm{C}$ before treatment with iodine solution. Plate segments were streaked with: 1-3, mutant strain TR1-5BW3414 transformed with pACYC184 (1), pSJ (2) and pCSR10 (3); 4, wild-type strain BW3414; 5, mutant strain transformed with pRsmA; 6, mutant strain TR1-5BW3414.

pattern of the wild-type strain BW3414, indicating that the glycogen-overproducing phenotype of the TR1-5BW3414 mutant was suppressed by RsmA $A_{P m}$. The TR1-5BW3414 mutants transformed with pSJ or pCSR10 showed a yellow staining pattern, suggesting that $\mathrm{RsmA}_{\mathrm{Pm}}$ and CsrA had similar abilities to suppress glycogen production by the mutant. These results suggested that $r s m A_{\text {Pm }}$ could complement the glycogen-excess phenotype of the $\operatorname{cs} r A$ mutant and that $\mathrm{RsmA}_{\mathrm{Pm}}$ had similar functions to CsrA.

\section{Effect of RsmA $A_{P m}$ on the swimming and swarming activities of Proteus mirabilis P19}

The above results suggested that the cloned $r s m A_{\mathrm{Pm}}$ gene was a true csrA homologue. Because CsrA and its homologue RsmA regulate motility in Escherichia coli and Erwinia species, the effect of RsmA $A_{P m}$ on the swimming and swarming activities of Proteus mirabilis was examined. Because expression of $r s m A_{\mathrm{Pm}}$ from a high-copy-number vector, such as pZErO2.1 or pCR2.1, in Proteus mirabilis, resulted in inhibition of growth (unpublished observations), the $r s m A_{\mathrm{Pm}}$ gene and its flanking sequences were cloned into the low-copy-number vector pACYC184 (Table 1) to generate pRsmA. The pRsmA plasmid was transformed into Proteus mirabilis P19 to establish an RsmA $\mathrm{Pm}_{\text {-expressing }}$ strain. As shown in Fig. 4, while Proteus mirabilis P19 transformed with the pACYC184 vector swarmed normally, the RsmA $A_{P m}$-expressing Proteus mirabilis strain, which expresses $\mathrm{Rsm}_{\mathrm{Pm}}$ from its native promoter, lost its ability to swarm. In contrast, the swimming motility of Proteus mirabilis was not affected by the presence of $\mathrm{RsmA}_{\mathrm{Pm}}$ (unpublished observations). These results indicated that RsmA $_{\text {Pm }}$ could specifically inhibit the swarming activity of Proteus mirabilis P19.

\section{Effect of RsmA $A_{P m}$ on swarming differentiation and virulence factor expression in Proteus mirabilis}

Swarming motility is associated with the expression of virulence factors in Proteus mirabilis (Allison \& Hughes, 1991; Allison et al., 1992; Liaw et al., 2000). Because RsmAPm inhibited the swarming activity of Proteus mirabilis P19, it was of interest to determine whether $\mathrm{RsmA}_{\mathrm{Pm}}$ could also inhibit swarming differentiation and virulence factor expression in Proteus mirabilis. The $\mathrm{RsmA}_{\mathrm{Pm} \text {-expressing Proteus }}$ mirabilis P19 strain and the vector-transformed Proteus mirabilis P19 strain were spread on to LB swarming plates and the cell length (as an indicator of swarming differentiation) and expression of virulence factors were determined $2 \mathrm{~h}$ after seeding and hourly thereafter. Proteus mirabilis transformed with the pACYC184 vector expressed haemolysin, protease, urease and flagellin in the same differentiationdependent manner as the parental Proteus mirabilis P19 strain (Fig. 5) (Liaw et al., 2001). They differentiated to the longest cells $4 \mathrm{~h}$ post-seeding and expressed the highest levels of these virulence factors 4 or $5 \mathrm{~h}$ post-seeding. In contrast, the $\mathrm{RsmA}_{\mathrm{Pm}}$-expressing Proteus mirabilis strain did not differentiate into long cells and expressed virulence factors at only a basal level during the whole differentiation cycle (Fig. 5). These results indicated that RsmA $A_{P m}$ could inhibit swarming differentiation and virulence factor expression in Proteus mirabilis.

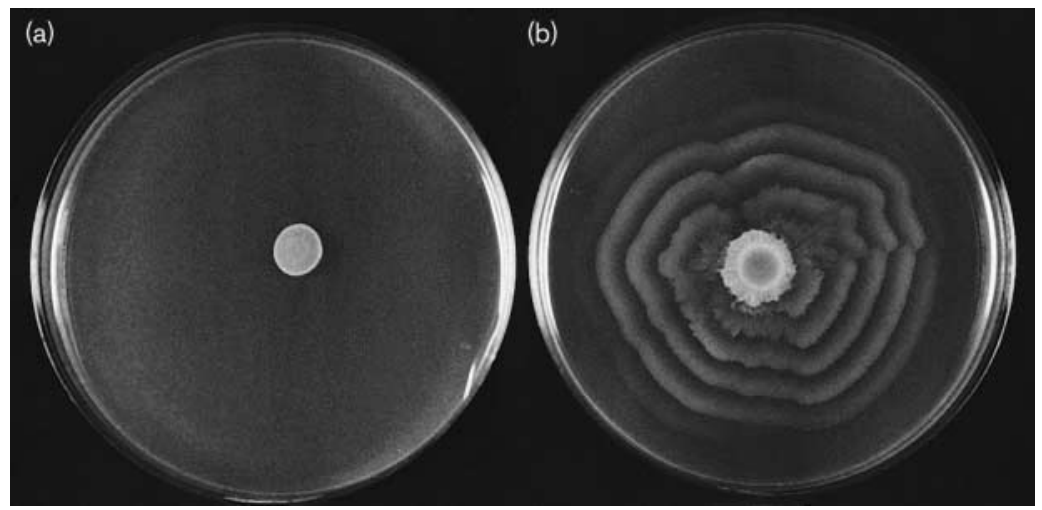

Fig. 4. Swarming of pRsmA-transformed (a) and pACYC184-transformed (b) Proteus mirabilis $\mathrm{P} 19$ on LB swarming plates. Aliquots $(5 \mu \mathrm{l})$ of bacterial culture were inoculated centrally on to LB swarming plates. The plates were incubated at $37{ }^{\circ} \mathrm{C}$ and observed after $10 \mathrm{~h}$ incubation. 

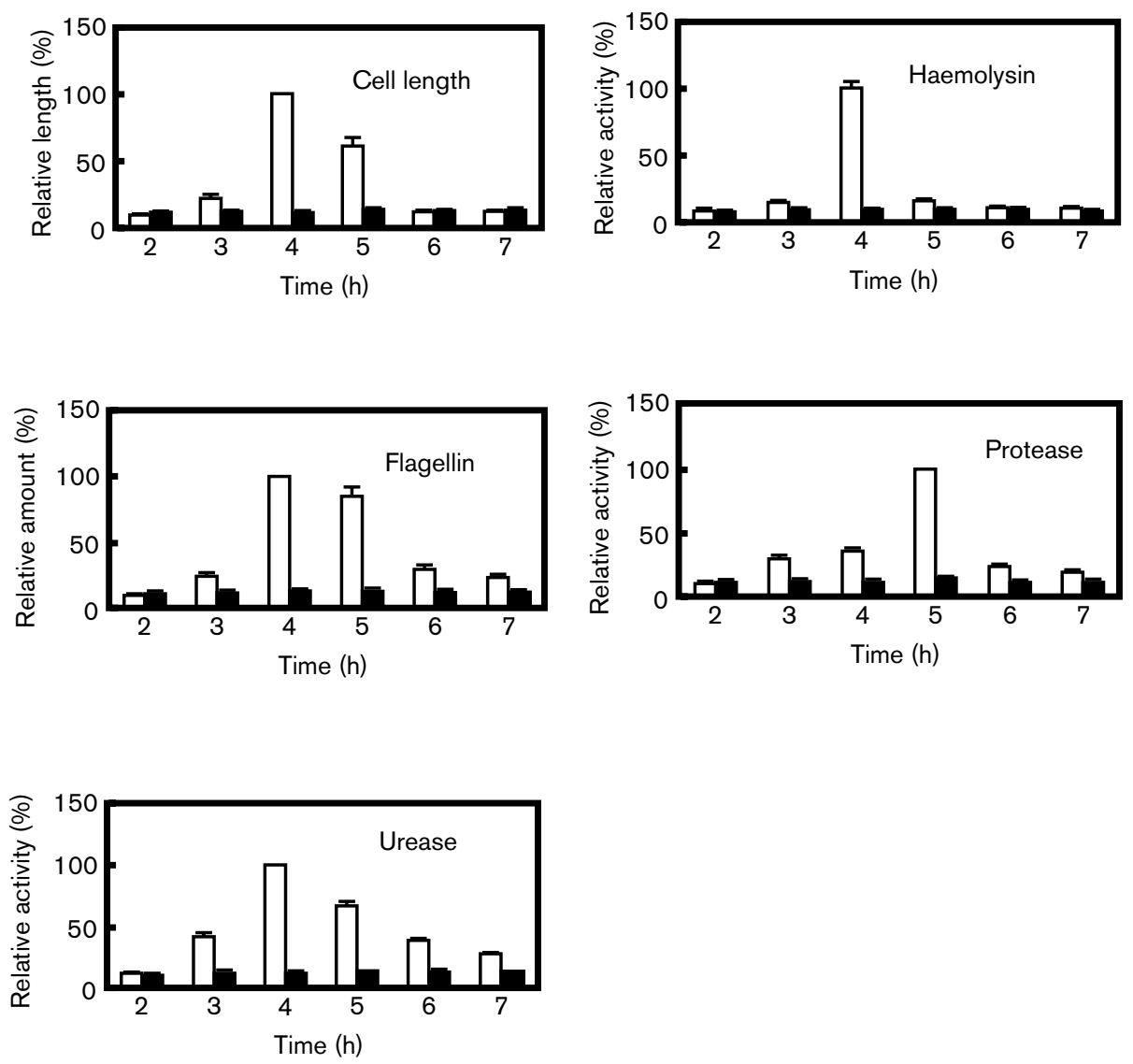

Fig. 5. Cell length and expression of virulence factors after plating of pACYC184-transformed (open bars) and pRsmA-transformed (filled bars) Proteus mirabilis P19 on LB agar plates and incubation at $37^{\circ} \mathrm{C}$. The increase in cell length was taken as a sign of cell (swarming) differentiation. For protease activity measurements, the value obtained with the pACYC184-transformed Proteus mirabilis $\mathrm{P} 19$ at $5 \mathrm{~h}$ post-seeding was set at $100 \%$ and all other values were expressed relative to this value. For all other measurements, the values obtained with the pACYC184-transformed Proteus mirabilis P19 at 4 h post-seeding were set at $100 \%$.

The data represent means of three independent experiments with standard deviations.

\section{Effect of RsmA Pm $_{\text {on mRNA stability }}$}

Because both Rsm $\mathrm{A}_{\mathrm{Ecc}}$ and CsrA regulate gene expression by affecting the stability of mRNA (Liu et al., 1995, 1998), it was possible that $\mathrm{RsmA}_{\mathrm{Pm}}$ inhibited virulence-gene expression through a similar mechanism. Therefore, the stability of haemolysin mRNAs isolated from the vector-transformed Proteus mirabilis $\mathrm{P} 19$ and pRsmA-transformed Proteus mirabilis $\mathrm{P} 19$ was compared. As shown in Fig. 6, the haemolysin mRNA in the RsmA $\mathrm{Pm}_{\mathrm{Pm}}$-transformed cells was completely degraded $8 \mathrm{~min}$ after rifampicin treatment, while that in the vector-transformed cells was not. These results indicated that $\mathrm{RsmA}_{\mathrm{Pm}}$ promoted mRNA degradation in Proteus mirabilis P19. Therefore, RsmA $A_{P m}$, like CsrA and $R s m A_{E c c}$, could inhibit virulence factor expression by affecting mRNA stability.

\section{Rsm $_{E c c}$ and RsmAsm trans-suppress swarming and virulence factor expression in Proteus mirabilis P19}

To investigate whether swarming and virulence factor ex- pression in Proteus mirabilis could also be inhibited by other RsmA homologues, the pSA1 plasmid (Table 1), which contained the $r s m A_{\mathrm{Ecc}}$ gene ( $r s m A$ from Erwinia carotovora subsp. carotovora) under the control of its native promoter, was transformed into Proteus mirabilis. As shown in Figs 7 and 8, while the vector-transformed Proteus mirabilis could differentiate, swarm and express virulence factors normally, the pSA1-transformed Proteus mirabilis strain lost its abilities to differentiate, swarm and express normal levels of virulence factors. Similarly, RsmA $A_{S m}$ (RsmA encoded by Serratia marcescens) also inhibited the ability of Proteus mirabilis to swarm and express virulence factors (unpublished observations). Together, these data confirmed that swarming and virulence factor expression in Proteus mirabilis could be suppressed by RsmA $A_{\mathrm{Pm}}$ and its homologues.

\section{DISCUSSION}

In many host-pathogen interactions, disease development requires co-ordinated expression of sets of genes in response to various signals and environmental cues (Cotter \& Miller, 
1998). Regulation of these genes is subject to both transcriptional and post-transcriptional control. RsmA-RsmB constitutes an important regulatory system responsible for posttranscriptional regulation (Liu et al., 1998; Cui et al., 1999). RsmA, an RNA-binding protein, promotes the decay of many mRNA species (Liu et al., 1998). RsmB, an untranslated regulatory RNA, on the other hand, neutralizes the effect of RsmA by forming a ribonucleoprotein complex with the latter (Liu et al., 1998). The RsmA regulatory system has been conserved in many enterobacterial species (Romeo et al., 1993; Cui et al., 1995; White et al., 1996) and has been shown to control diverse phenotypes including motility and expression of virulence factors (Cui et al., 1995; Mukherjee et al., 1996). In this study, we cloned the $r s m A_{\mathrm{Pm}}$ gene from Proteus mirabilis and investigated the effect of $\mathrm{RsmA}_{\mathrm{Pm}}$ on swarming and virulence factor expression in Proteus mirabilis. $r s m A_{\mathrm{Pm}}$ was found to complement the defectiveness of an Escherichia coli csrA ( $r s m A$ homologue) mutant (Romeo et al., 1993) and could act as rsmA $A_{\mathrm{Ecc}}$ (Ang et al., 2001) and $r s m A_{\mathrm{Sm}}$ (Ang et al., 2001) to suppress swarming and virulence factor expression in Proteus mirabilis.

Several lines of evidence suggest that the $r s m A_{\mathrm{Pm}}$ gene we cloned is a true $r s m A$ homologue. Firstly, the DNA sequence and the predicted product of $r s m A_{\mathrm{Pm}}$ showed high similarity to $r s m A$ cloned from other bacteria (Fig. 2). Secondly, like other RsmAs, the predicted $r s m A_{\mathrm{Pm}}$ product bore a putative

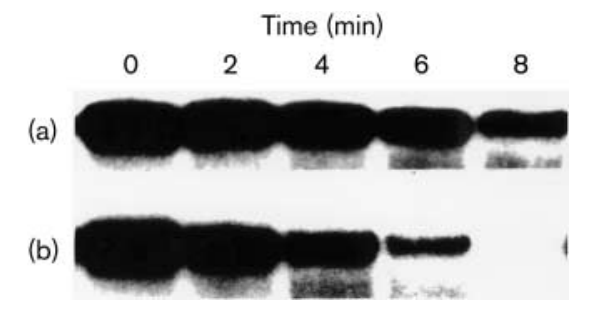

Fig. 6. Stability of the haemolysin mRNA in pACYC184-transformed (a) and pRsmA-transformed (b) Proteus mirabilis P19. Rifampicin $\left(400 \mu \mathrm{g} \mathrm{ml}^{-1}\right.$ ) was added to the cultures at an $\mathrm{OD}_{600}$ of 0.5 and RNA was extracted $0,2,4,6$ and 8 min after the addition of rifampicin. Northern hybridization was performed at $58^{\circ} \mathrm{C}$ with the DIG-labelled haemolysin probe. Each lane in row (a) was loaded with $10 \mu \mathrm{g}$ total RNA and each lane in row (b) was loaded with $20 \mu \mathrm{g}$ total RNA.
RNA-binding motif (Siomi et al., 1994). Thirdly, $r s m A_{\mathrm{Pm}}$ could complement the glycogen-excess phenotype of an Escherichia coli csrA mutant (Fig. 3). Furthermore, complementation of the $c s r A$ mutant with $r s m A_{\mathrm{Pm}}$ also restored the cell length to wild-type and abolished its formation of a biofilm (unpublished observations). Fourthly, RsmA $A_{P m}$ could act as RsmA $A_{E c c}$ and $R s m A_{S m}$ to suppress swarming and virulence factor expression in Proteus mirabilis.

The role of RsmA/CsrA in regulating bacterial virulence is of considerable interest and has been established in Erwinia species that are plant pathogens. A transposon-insertion mutation in rsmA in Erwinia caused hypervirulence, overproduction of lytic enzymes and elevation of their corresponding transcripts (Cui et al., 1995; Chatterjee et al., 1995). In Pseudomonas fluorescens, RsmA is also a negative regulator of virulence factor expression (Blumer et al., 1999). Motility is an important survival mechanism and a distinct advantage for host-adapted species. Overexpression of rsmA has been demonstrated to suppress motility and flagella production in Erwinia carotovora subsp. carotovora (Mukherjee et al., 1996). Our finding that $\mathrm{RsmA}_{\mathrm{Pm}}$ could suppress swarming and virulence factor expression in Proteus mirabilis is consistent with the above observations. Our results also suggest that Rsm $A_{P m}$ may play an important role in regulating virulence in Proteus mirabilis.

RsmA regulates gene expression by controlling mRNA stability and, thus, is a global regulator of gene expression in many bacteria (Romeo, 1998). RsmA $A_{P m}$ also regulated gene expression through regulating mRNA stability and could promote mRNA degradation (Fig. 6). It is possible that the activity of Rsm $A_{\mathrm{Pm}}$ must be rigorously controlled in the cells (Cui et al., 1999; Mukherjee et al., 1998). Overexpression of rsmA from high-copy-number plasmids or artificial strong promoters is generally detrimental to cell physiology and, in certain hosts, is even lethal (Cui et al., 1999). In our study, overexpression of $r s m A_{\mathrm{pm}}$ from the highcopy-number plasmids pZErO2.1 and pCR2.1 was inhibitory to the growth of Proteus mirabilis and Escherichia coli, whereas $r s m A_{\mathrm{Pm}}$ expressed from the low-copy-number pACYC184 was not (unpublished observations). These observations suggest that the level of $\mathrm{RsmA}_{\mathrm{Pm}}$ must be delicately regulated in Proteus mirabilis and are supported by findings implying that the $r s m A_{\mathrm{Pm}}$ gene is essential for Proteus mirabilis. Repeated attempts to isolate $r s m A_{\mathrm{Pm}^{-}}{ }^{-}$

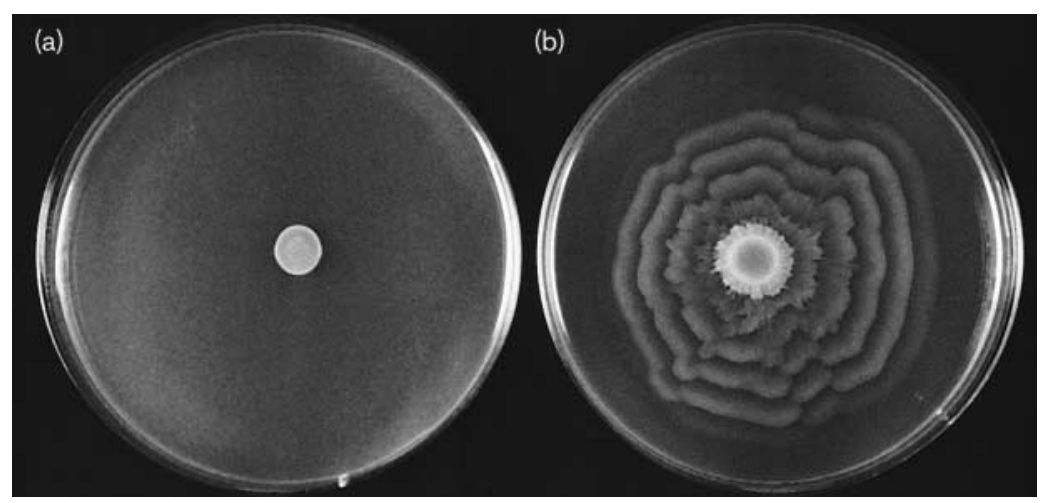

Fig. 7. Swarming of pSA1-transformed (a) and pACYC184-transformed (b) Proteus mirabilis P19 on LB swarming plates. Aliquots $(5 \mu \mathrm{l})$ of bacterial culture were inoculated centrally onto LB swarming plates. The plates were incubated at $37^{\circ} \mathrm{C}$ and observed after $10 \mathrm{~h}$ incubation. 

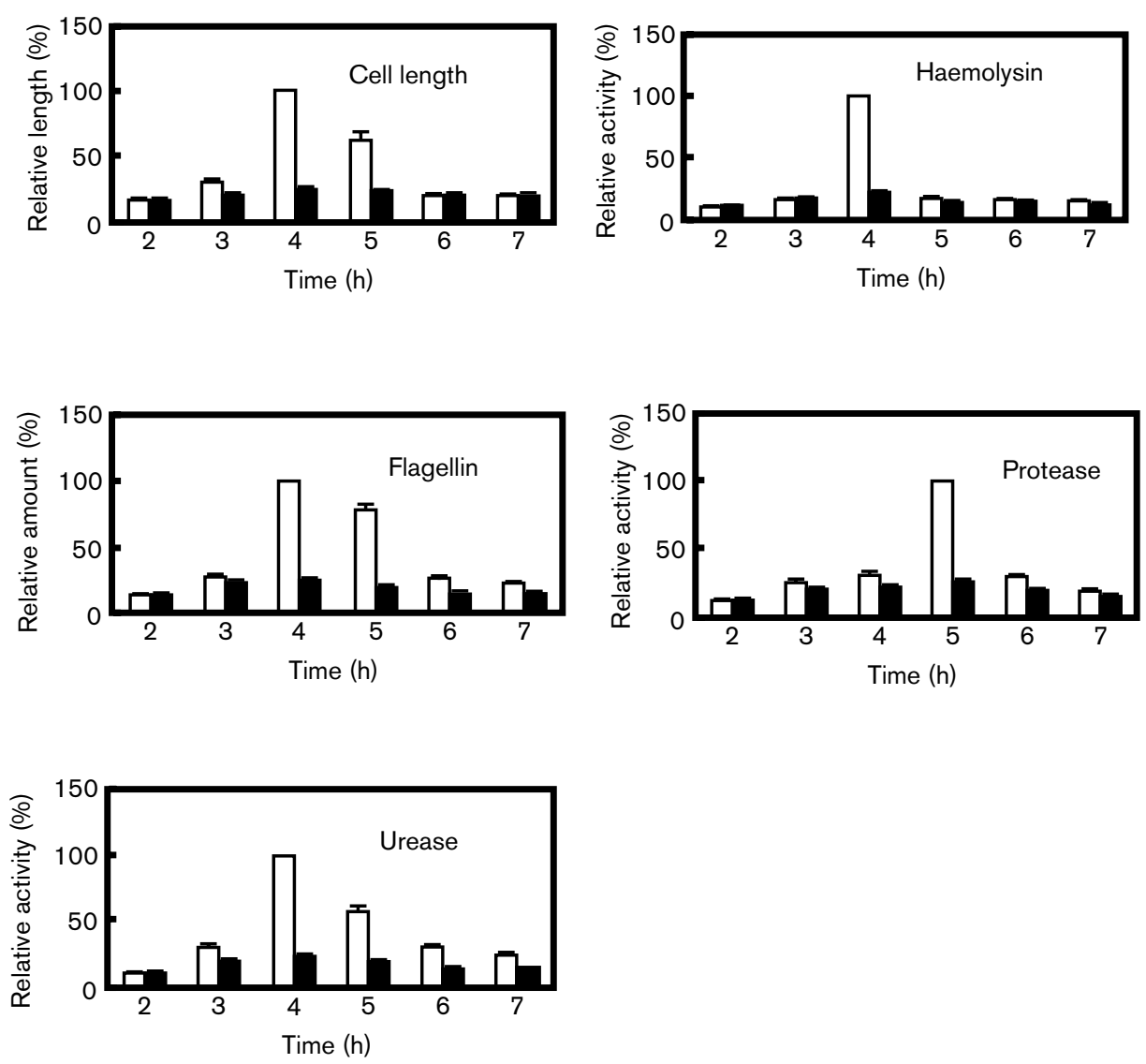

Fig. 8. Cell length and expression of virulence factors after plating of pACYC184-transformed (open bars) and pSA1-transformed (filled bars) Proteus mirabilis P19 on LB agar plates and incubation at $37^{\circ} \mathrm{C}$. For further details see legend to Fig. 5.

knockout Proteus mirabilis mutants by using the $\mathrm{pKO} 3$ genereplacement vector (Link et al., 1997) and the screening of $\sim 10000$ clones have proved unsuccessful. rsmA/csrA is not essential in Escherichia coli or Serratia marcescens (Romeo et al., 1993; Ang et al., 2001). However, a csrA-knockout mutation is deleterious in Salmonella enterica serovar Typhimurium (Altier et al., 2000) and possibly also in Yersinia and Legionella species (T. Romeo, personal communication). Further experiments from construction of $r s m A_{\mathrm{Pm}}$ temperature-sensitive mutants should be performed to determine the essentiality of $r s m A_{\mathrm{Pm}}$ in Proteus mirabilis.

Regulation of swarming and virulence factor expression is a complex process and involves many factors and regulatory pathways (Fraser \& Hughes, 1999). Previously, we demonstrated that RsbA, a sensor kinase homologue of the bacterial two-component system, was a negative regulator of swarming and virulence factor expression in Proteus mirabilis (Liaw et al., 2001). rsbA-defective Proteus mirabilis mutants exhibit a super-swarming phenotype and overproduce virulence factors. When $r s m A_{\mathrm{Pm}}$ was transformed into these mutants, swarming was drastically suppressed (unpublished observations). These results suggest that the RsbA regulatory pathway and the RsmA $A_{P m}$ regulatory pathway may cross-talk to each other. In Pseudomonas fluorescens and Erwinia caroto- vora subsp. carotovora, the two-component system GacA/ GacS has been shown to control the production of extracellular enzymes by regulating the expression of the rsmA/ rsmB system (Mukherjee et al., 1998; Cui et al., 2001). It is possible that RsbA may also regulate swarming and virulence factor expression through modulating the expression of the $r s m A / r s m B$ system. Experiments aimed at elucidating the relationship between RsbA and $\mathrm{RsmA}_{\mathrm{Pm}}$ are in progress.

In addition to $r s m A_{\mathrm{Pm}}$, we also found that $r s m A$ homologues exist in many bacteria including Pseudomonas aeruginosa, Vibrio parahaemolyticus, Morganella morganii, Klebsiella pneumoniae, Aeromonas hydrophila, Citrobacter diversus, Helicobacter pylori and Streptococcus sanguis (unpublished observations). Whether these rsmA homologues also regulate virulence in these bacteria is of interest and warrants further investigation.

\section{ACKNOWLEDGEMENTS}

We thank Dr Tony Romeo for providing us with Escherichia coli strains TR1-5BW3414 and BW3414 and for helpful discussions. This work was supported by grants from the National Science Council and the National Taiwan University Hospital, Taipei, Taiwan. 


\section{REFERENCES}

Allison, C. \& Hughes, C. (1991). Bacterial swarming: an example of prokaryotic differentiation and multicellular behaviour. Sci Prog 75, 403-422.

Allison, C., Lai, H. C. \& Hughes, C. (1992). Co-ordinate expression of virulence genes during swarm-cell differentiation and population migration of Proteus mirabilis. Mol Microbiol 6, 1583-1591.

Allison, C., Lai, H. C., Gygi, D. \& Hughes, C. (1993). Cell differentiation of Proteus mirabilis is initiated by glutamine, a specific chemoattractant for swarming cells. Mol Microbiol 8, 53-60.

Altier, C., Suyemoto, M. \& Lawhon, S. D. (2000). Regulation of Salmonella enterica serovar Typhimurium invasion genes by csrA. Infect Immun 68, 6790-6797.

Ang, S., Horng, Y. T., Shu, J. C. \& 7 other authors (2001). The role of RsmA in the regulation of swarming motility in Serratia marcescens. J Biomed Sci 8, 160-169.

Belas, R., Erskine, D. \& Flaherty, D. (1991). Proteus mirabilis mutants defective in swarmer cell differentiation and multicellular behavior. J Bacteriol 173, 6279-6288.

Belas, R., Goldman, M. \& Ashliman, K. (1995). Genetic analysis of Proteus mirabilis mutants defective in swarmer cell elongation. J Bacteriol 177, 823-828.

Blumer, C., Heeb, S., Pessi, G. \& Haas, D. (1999). Global GacA-steered control of cyanide and exoprotease production in Pseudomonas fluorescens involves specific ribosome binding sites. Proc Natl Acad Sci U S A 96, 14073-14078.

Chatterjee, A., Cui, Y., Liu, Y., Dumenyo, C. K. \& Chatterjee, A. K. (1995). Inactivation of $r s m A$ leads to overproduction of extracellular pectinases, cellulases, and proteases in Erwinia carotovora subsp. carotovora in the absence of the starvation/cell density-sensing signal, $\mathrm{N}$-(3-oxohexanoyl)-L-homoserine lactone. Appl Environ Microbiol 61, 1959-1967.

Cotter, P. A. \& Miller, J. F. (1998). In vivo and ex vivo regulation of bacterial virulence gene expression. Curr Opin Microbiol 1, 17-26.

Cui, Y., Chatterjee, A., Liu, Y., Dumenyo, C. K. \& Chatterjee, A. K. (1995). Identification of a global repressor gene, rsmA, of Erwinia carotovora subsp. carotovora that controls extracellular enzymes, $\mathrm{N}$-(3oxohexanoyl)-L-homoserine lactone, and pathogenicity in soft-rotting Erwinia spp. J Bacteriol 177, 5108-5115.

Cui, Y., Mukherjee, A., Dumenyo, C. K., Liu, Y. \& Chatterjee, A. K. (1999). $r s m C$ of the soft-rotting bacterium Erwinia carotovora subsp. carotovora negatively controls extracellular enzyme and harpin $\mathrm{Ecc}_{\mathrm{Ec}}$ production and virulence by modulating levels of regulatory RNA ( rsmB) and RNA-binding protein (RsmA). J Bacteriol 181, 6042-6052.

Cui, Y., Chatterjee, A. \& Chatterjee, A. K. (2001). Effects of the twocomponent system comprising GacA and GacS of Erwinia carotovora subsp. carotovora on the production of global regulatory rsmB RNA, extracellular enzymes, and harpin ${ }_{\mathrm{Ecc}}$. Mol Plant Microbe Interact 14, 516-526.

Devereux, J., Haeberli, P. \& Smithies, O. (1984). A comprehensive set of sequence analysis programs for the VAX. Nucleic Acids Res 12, 387-395.

Eberl, L., Molin, S. \& Givskov, M. (1999). Surface motility of Serratia liquefaciens MG1. J Bacteriol 181, 1703-1712.

Fleischmann, R. D., Adams, M. D., White, O. \& 37 other authors (1995). Whole-genome random sequencing and assembly of Haemophilus influenzae Rd. Science 269, 496-512.

Fraser, G. M. \& Hughes, C. (1999). Swarming motility. Curr Opin Microbiol 2, 630-635.

Fraser, G. M., Bennett, J. C. \& Hughes, C. (1999). Substrate-specific binding of hook-associated proteins by FlgN and FliT, putative chaperones for flagellum assembly. Mol Microbiol 32, 569-580.

Gaisser, S. \& Hughes, C. (1997). A locus coding for putative nonribosomal peptide/polyketide synthase functions is mutated in a swarming-defective Proteus mirabilis strain. Mol Gen Genet 253, 415-427.

Gibson, S. A. W. \& Macfarlane, G. T. (1988). Characterization of proteases formed by Bacteroides fragilis. J Gen Microbiol 134, 2231-2240.

Givskov, M., Eberl, L. \& Molin, S. (1997). Control of exoenzyme production, motility and cell differentiation in Serratia liquefaciens. FEMS Microbiol Lett 148, 115-122.

Gygi, D., Bailey, M. J., Allison, C. \& Hughes, C. (1995a). Requirement for FlhA in flagella assembly and swarm-cell differentiation by Proteus mirabilis. Mol Microbiol 15, 761-769.

Gygi, D., Rahman, M. M., Lai, H. C., Carlson, R., Guard-Petter, J. \& Hughes, C. (1995b). A cell-surface polysaccharide that facilitates rapid population migration by differentiated swarm cells of Proteus mirabilis. Mol Microbiol 17, 1167-1175.

Gygi, D., Fraser, G., Dufour, A. \& Hughes, C. (1997). A motile but nonswarming mutant of Proteus mirabilis lacks FlgN, a facilitator of flagella filament assembly. Mol Microbiol 25, 597-604.

Harshey, R. M. (1994). Bees aren't the only ones: swarming in gramnegative bacteria. Mol Microbiol 13, 389-394.

Harshey, R. M. \& Matsuyama, T. (1994). Dimorphic transition in Escherichia coli and Salmonella typhimurium: surface-induced differentiation into hyperflagellate swarmer cells. Proc Natl Acad Sci U S A 91, 8631-8635.

Hay, N. A., Tipper, D. J., Gygi, D. \& Hughes, C. (1999). A novel membrane protein influencing cell shape and multicellular swarming of Proteus mirabilis. J Bacteriol 181, 2008-2016.

Jones, B. D. \& Mobley, H. L. T. (1988). Proteus mirabilis urease: genetic organization, regulation, and expression of structural genes. J Bacteriol 170, 3342-3349.

Koronakis, V., Cross, M., Senior, B., Koronakis, E. \& Hughes, C. (1987). The secreted hemolysins of Proteus mirabilis, Proteus vulgaris, and Morganella morganii are genetically related to each other and to the alpha-hemolysin of Escherichia coli. J Bacteriol 169, 1509-1515.

Liaw, S.-J., Lai, H.-C., Ho, S.-W., Luh, K.-T. \& Wang, W.-B. (2000). Inhibition of virulence factor expression and swarming differentiation in Proteus mirabilis by p-nitrophenylglycerol. J Med Microbiol 49, $725-731$.

Liaw, S.-J., Lai, H.-C., Ho, S.-W., Luh, K.-T. \& Wang, W.-B. (2001). Characterisation of $p$-nitrophenylglycerol-resistant Proteus mirabilis super-swarming mutants. J Med Microbiol 50, 1039-1048.

Link, A. J., Phillips, D. \& Church, G. M. (1997). Methods for generating precise deletions and insertions in the genome of wild-type Escherichia coli: application to open reading frame characterization. J Bacteriol 179, $6228-6237$.

Liu, M. Y. \& Romeo, T. (1997). The global regulator CsrA of Escherichia coli is a specific mRNA-binding protein. J Bacteriol 179, 4639-4642.

Liu, M. Y., Yang, H. \& Romeo, T. (1995). The product of the pleiotropic Escherichia coli gene csrA modulates glycogen biosynthesis via effects on mRNA stability. J Bacteriol 177, 2663-2672.

Liu, M. Y., Gui, G., Wei, B., Preston, J. F., III, Oakford, L., Yuksel, U., Giedroc, D. P. \& Romeo, T. (1997). The RNA molecule CsrB binds to the global regulatory protein CsrA and antagonizes its activity in Escherichia coli. J Biol Chem 272, 17502-17510.

Liu, Y., Cui, Y., Mukherjee, A. \& Chatterjee, A. K. (1998). Characterization of a novel RNA regulator of Erwinia carotovora ssp. carotovora that 
controls production of extracellular enzymes and secondary metabolites. Mol Microbiol 29, 219-234.

Magni, C., Marini, P. \& de Mendoza, D. (1995). Extraction of RNA from gram-positive bacteria. Biotechniques 19, 880-884.

Mirel, D. B. \& Chamberlin, M. J. (1989). The Bacillus subtilis flagellin gene ( hag) is transcribed by the $\sigma^{28}$ form of RNA polymerase. J Bacteriol 171, 3095-3101.

Mukherjee, A., Cui, Y., Liu, Y., Dumenyo, C. K. \& Chatterjee, A. K. (1996). Global regulation in Erwinia species by Erwinia carotovora rsmA, a homologue of Escherichia coli csrA: repression of secondary metabolites, pathogenicity and hypersensitive reaction. Microbiology 142, 427-434.

Mukherjee, A., Cui, Y., Ma, W., Liu, Y., Ishihama, A., Eisenstark, A. \& Chatterjee, A. K. (1998). RpoS ( $\sigma-S)$ controls expression of $r s m A$, a global regulator of secondary metabolites, harpin, and extracellular proteins in Erwinia carotovora. J Bacteriol 180, 3629-3634.

Rauprich, O., Matsushita, M., Weijer, C. J., Siegert, F., Esipov, S. E. \& Shapiro, J. A. (1996). Periodic phenomena in Proteus mirabilis swarm colony development. J Bacteriol 178, 6525-6538.

Romeo, T. (1998). Global regulation by the small RNA-binding protein CsrA and the non-coding RNA molecule CsrB. Mol Microbiol 29, 1321-1330.
Romeo, T., Gong, M., Liu, M. Y. \& Brun-Zinkernagel, A. M. (1993). Identification and molecular characterization of $c s r A$, a pleiotropic gene from Escherichia coli that affects glycogen biosynthesis, gluconeogenesis, cell size, and surface properties. J Bacteriol 175, 4744-4755.

Siomi, H., Choi, M., Siomi, M. C., Nussbaum, R. L. \& Dreyfuss, G. (1994). Essential role for KH domains in RNA binding: impaired RNA binding by a mutation in the $\mathrm{KH}$ domain of FMR1 that causes fragile $\mathrm{X}$ syndrome. Cell 77, 33-39.

Uphoff, T. S. \& Welch, R. A. (1990). Nucleotide sequencing of the Proteus mirabilis calcium-independent hemolysin genes ( $h p m A$ and $h p m B)$ reveals sequence similarity with the Serratia marcescens hemolysin genes (shlA and shlB). J Bacteriol 172, 1206-1216.

Warren, J. W., Tenney, J. H., Hoopes, J. M., Muncie, H. L. \& Anthony, W. C. (1982). A prospective microbiologic study of bacteriuria in patients with chronic indwelling urethral catheters. J Infect Dis 146, 719-723.

Wei, B. L., Brun-Zinkernagel, A. M., Simecka, J. W., Prüß, B. M., Babitzke, P. \& Romeo, T. (2001). Positive regulation of motility and flhDC expression by the RNA-binding protein CsrA of Escherichia coli. Mol Microbiol 40, 245-256.

White, D., Hart, M. E. \& Romeo, T. (1996). Phylogenetic distribution of the global regulatory gene csrA among eubacteria. Gene 182, 221-223. 